\title{
Correction to: Genome-wide analysis of Rf-PPR-like (RFL) genes and a new InDel marker development for Rf1 gene in cytoplasmic male sterile CMS-D2 Upland cotton
}

ZHANG Bingbing, ZHANG Xuexian, GUO Liping, QI Tingxiang, WANG Hailin, TANG Huini, QIAO Xiuqin, SHAHZAD Kashif, XING Chaozhu* and WU Jianyong*

\section{Correction to: J Cotton Res}

https://doi.org/10.1186/s42397-018-0013-y

In the original publication of this article (Zhang et al. 2018) the first name and surname of the eighth author are in reverse order. The correct name of the eighth author should be SHAHZAD Kashif. In 'Authors' contributions', 'Kashif S' should be 'Shahzad K'. The original publication has been corrected.

Received: 3 December 2018 Accepted: 3 December 2018

Published online: 24 December 2018

\section{Reference}

Zhang, et al. J Cotton Res. 2018;1:12 https://doi.org/10.1186/s42397-018-0013-y.

\footnotetext{
* Correspondence: chaozhuxing@126.com; dr.wujianyong@live.cn

State Key Laboratory of Cotton Biology/Institute of Cotton Research of

Chinese Academy of Agricultural Sciences, 38 Huanghe Dadao, Anyang

455 000, Henan, China
} 